\title{
Decitabine, differently from DNMT1 silencing, exerts its antiproliferative activity through p21 upregulation in malignant pleural mesothelioma (MPM) cells
}

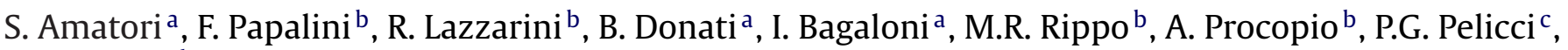 \\ A. Catalano ${ }^{\mathrm{b}}$, M. Fanelli ${ }^{\mathrm{a}, *}$ \\ a Molecular Pathology and Oncology Lab. “M.Paola”, Department of Biomolecular Sciences, University of Urbino “Carlo Bo”, Via Arco d'Augusto 2, 61032 Fano, PU, Italy \\ ${ }^{\mathrm{b}}$ Department of Molecular Pathology and Innovative Therapies, Marche University, Ancona, Italy \\ ${ }^{\mathrm{c}}$ Department of Experimental Oncology, European Institute of Oncology, Milan, Italy
}

\section{A R T I C L E I N F O}

\section{Article history:}

Received 8 May 2008

Received in revised form 21 October 2008

Accepted 19 January 2009

\section{Keywords:}

Mesothelioma

DNA methyltransferases

DNA methylation

Satellite 2

Epigenetic

p21

\begin{abstract}
A B S T R A C T
Malignant pleural mesothelioma (MPM) is a locally aggressive neoplasm, principally linked to asbestos fibres exposure. Strong evidences associate this pollutant with induction of DNA breaks, aberrant chromosomes segregation and important chromosomal rearrangements, considered crucial events in malignant transformation. A considerable contribution to cellular transformation in MPM is also given by the presence of high genomic instability, as well as by the increased DNA methylation, and consequent decreased expression, of tumor-suppressor genes. In this study we first demonstrated that MPM cells are characterized by a decreased methylation level of pericentromeric DNA sequences which can justify, at least in part, the genomic instability observed in this neoplasia. Concomitantly, we found a paradoxical increased expression of DNMT1, the most expressed DNA methyltransferases in MPM cells, DNMT3a and all five isoforms of DNMT3b. Thus, we compared two experimental strategies, DNMT1 silencing and usage of a demethylating agent (5-aza-2'-deoxycytidine or Decitabine), both theoretically able to revert the locally hypermethylated phenotype and considered potential future therapeutic approaches for MPM. Interestingly, both strategies substantially decrease cell survival of MPM cells but the antitumor activity of Decitabine, differently from DNMT1 silencing, is mediated, at least in part, by a p53-independent p21 upregulation, and is characterized by the arrest of MPM cells at the G2/M phase of the cell cycle. These results indicate that the two approaches act probably through different mechanisms and, thus, that DNMT1 silencing can be considered an effective alternative to Decitabine for cancer treatment.
\end{abstract}

(C) 2009 Published by Elsevier Ireland Ltd.

\section{Introduction}

Malignant pleural mesothelioma (MPM) is an aggressive neoplasia originating from pleural mesothelial cells and epidemiologically associated with asbestos fibres exposure. The molecular mechanisms responsible for cellular transformation are poorly understood but there are evidences that strongly link the asbestos fibres with induction of typical chromosomal aberrations found in MPM cells [1,2].

In the last years, many evidences have been accumulated about the epigenetic alterations of cancer cells. Regarding the genomic DNA methylation, tumor cells are paradoxically characterized by two distinct phenomena: hypermethylation of $\mathrm{CpG}$ islands, often in the contest of tumor-suppressor gene promoters, and hypomethylation of $\mathrm{CpG}$ dinucleotides that are highly represented in pericentromeric regions, such as satellite 2 repeats [3-6].

\footnotetext{
* Corresponding author. Tel.: +39 0721 862832; fax: +39 0721862832.

E-mail address: mirco.fanelli@uniurb.it (M. Fanelli).
}

Functionally, these perturbations may be involved, respectively, in tumor-suppressor genes silencing and genomic destabilization, crucial events in tumor development. Mesothelioma cells seem to recapitulate the epigenetic features of solid tumors since the presence of high genomic instability and a pattern of transcriptionally repressed tumor-suppressor genes, through DNA hypermethylation, has been demonstrated [7-12].

The molecular mechanisms responsible for the altered DNA methylation pattern in cancer are still unknown. Genetic alterations of DNA methyltransferases (DNMTs) coding sequences seem to be not involved in this phenomenon: human Immunodeficiency, Centromeric instability and Facial abnormalities (ICF) syndrome remains the unique disease in which satellite 2 demethylation and genomic instability are correlated to DNMT3b mutations, even if in only $60-70 \%$ of ICF patients [13-15].

Moreover, altered pattern of DNA methyltransferases expression was reported as possible mechanism responsible for either decreased global DNA methylation (e.g. DNMT3b4 dominantnegative isoform overexpression in hepatocarcinoma, DNMT3a loss of expression in glioblastoma) and promoter-associated CpG island 
hypermethylation (e.g. overexpression of DNMT1 in almost all kind of neoplasia) $[4,16]$.

Mainly, two strategies have been considered to revert the local hypermethylation in cancer: usage of demethylating agents, such as 5-aza-2'-deoxycytidine (or Decitabine), and interference with DNMTs expression. Decitabine has been tested in several Phase I, II and III clinical trials founding the most promising benefits in leukemia patients, specially those affected by myelodysplastic syndrome (MDS) [17-19]. For this reason Decitabine has been approved for the treatment of MDS showing excellent capability to reactivate the expression of several methylated genes [20]. Although the therapeutic abilities of Decitabine for the treatment of hematopoietic malignancies have been demonstrated, the activity in solid tumors remains unclear and severe toxicities related to prolonged myelosuppression have to be considered [21]. Recently, the potential therapeutic properties of Decitabine have been investigated in a Phase I trial study involving patients with thoracic malignancies, MDS cases included [22]. With a similar aim, DNMT1 silencing procedure has been transiently applied to a variety of cellular models (e.g. lung cancer, breast cancer, gastric cancer) obtaining interesting results in terms of decreased proliferation and induction of programmed cell death [23-25]. In this study we addressed the question whether Decitabine treatment or DNMT1 silencing could be considered equivalent strategies for cancer treatment. We first characterized the epigenetic status of MPM cells monitoring both satellite 2 methylation levels, as marker of genomic stability, and DNMTs expression pattern. Secondly, we compared the biological MPM cellular response to either DNMT1 silencing or demethylating (Decitabine) treatment. Finally, we investigated the role of p21 expression in the MPM antiproliferative response to Decitabine.

\section{Materials and methods}

\subsection{Cell cultures and treatments}

Immortalized human malignant pleural mesothelioma $\mathrm{NCI}-\mathrm{H} 28$ cells were obtained from the American Type Culture Collection (ATTC, Rochville, MD, USA). Primary normal mesothelial cells (HMC2) and primary MPM cells (MES-SS 01, MES-PR 99) were established from pleural effusions and tumor specimens, respectively, and characterized as previously described [26]. All cellular populations were cultured in DMEM (Cambrex, Walkersville, MD, USA) supplemented with $10 \%$ fetal bovine serum (FBS), $1 \%$ penicillin-streptomycin, $1 \%$ glutamine. Decitabine (or 5-aza2'-deoxycytidine-Sigma, Saint Louis, MO, USA) treatments were performed at indicated doses and timing, adding the compound at each $48 \mathrm{~h}$.

\subsection{Satellite 2 DNA methylation analysis and quantitative RT-PCR}

Pericentromeric satellite 2 CpG methylation levels were monitored by southern blotting analysis as described [4]. RNA isolation, real-time RT-PCR assay and analysis were performed as described $[4,27]$. Each sample was analysed using ribosomal protein RPLPO as endogenous reference gene for mRNA normalization and valuated as fold-induction compared with the normal (not neoplastic) sample. Quantification of p21 expression was conducted by using the following primers: sense, 5'-TACCCTTGTGCCTCGCTCAG-3'; antisense, 5'-GGCGGATTAGGGCTTCCTCT-3'.

\subsection{Infection, cell cycle analysis, and western blot}

Lentiviral production was performed co-transfecting 293T cells with pLL3.7-MTsh1 or pLL3.7-p21sh1 (or pLL3.7 empty vector) in combination with packaging plasmids as described [28]. Briefly, supernatant of transiently transfected $293 \mathrm{~T}$ cells was recovered after $36 \mathrm{~h}$ and two cycles of infection of $\mathrm{H} 28$ cells were performed ( $6 \mathrm{~h}$ each cycle) within $48 \mathrm{~h}$. EGFP positivity of target cells was monitored to verify the efficiency of infection that approximately reached $90-95 \%$. Stable EGFP expression was monitored for 1 month and, in the case of pLL3.7 and pLL3.7-p21sh1 infection, a negligible decrease of GFP positive cells was observed.

Cell cycle analysis was performed fixing the cells in ice-cold 70\% ethanol solution $\left(16 \mathrm{~h}\right.$ at $\left.+4{ }^{\circ} \mathrm{C}\right)$ and resuspending them in propidium iodide staining solution ( $0.1 \%$ sodium citrate, $0.1 \%$ Triton X-100, $250 \mu \mathrm{g} / \mathrm{ml}$ RNase A, $50 \mu \mathrm{g} / \mathrm{ml}$ propidium iodide). Cytofluorimetric acquisitions and sample analysis were performed by BD FACScan flow cytometer (BD Biosciences, San Jose, CA, USA) and FlowJo 8.6.3 software (Tree Star, Inc., Ashland, OR, USA), respectively.

Western blot analysis were performed as previously described [29].

\subsection{DNA laddering assay}

DNA laddering assay was carried out as follow. About $2 \times 10^{6}$ cells were harvested by trypsinization, washed once with ice-cold $1 \times$ PBS and incubated in $2 \mathrm{ml}$ of $1 \times$ TBS, $0.5 \%$ Tween $20,1 \mathrm{mM}$ EDTA for $30 \mathrm{~min}$ at $+4{ }^{\circ} \mathrm{C}$. Samples were centrifuged at $1200 \mathrm{rpm}$ for $5 \mathrm{~min}$ at $+4{ }^{\circ} \mathrm{C}$ and pellets incubated in $0.5 \mathrm{ml}$ of $0.1 \%$ SDS solution for 30 min at RT. DNA was then purified by QIAquick Gel Extraction Kit (Qiagen, Hilden, Germany), separated by $2 \%$ agarose gel, and detected by ethidium bromide staining.

\section{Results}

\subsection{Satellite 2 pericentromeric DNA hypomethylation and DNMTs} altered expression in MPM cells

Repetitive (ATTCCATTCG) 2 DNA sequence is highly represented in regions localized in the pericentromere of chromosome 1 and 16 , named satellite $2[30,31]$. The methylation status of satellite 2 sequences was investigated by a methylation-sensitive endonuclease-based assay revealing decreased CpG methylation levels in two primary malignant mesothelioma cellular populations (MES-SS 01, MES-PR 99) and in H28 immortalized MPM cell line, if compared with normal mesothelial cells (HMC2) (Fig. 1a).

In order to establish differences in the expression of DNA methyltransferases between normal and tumor cells, that could justify the observed loss of satellite 2 methylation, we analyzed the mRNA levels of DNMT1, DNMT3a and all five isoforms of DNMT3b, by realtime quantitative RT-PCR, in either primary MPM cells (MES-SS 01, MES-PR 99) and normal mesothelial cells (HMC2). Primary MPM cells showed an increased expression of DNMT1 (4.4-7.2 folds) concomitantly with a less pronounced increased expression of DNMT3a (1.7-3.8 folds) and variable higher levels of DNMT3b (2-6.8 folds) (Fig. 1b). However, DNMT1 resulted the most expressed form of DNA methyltransferase ( $>85-90 \%$ of total DNMTs) representing the main source of methyltransferase activity in MPM cells (Fig. 1b).

\subsection{Stable silencing of DNMT1 expression induces decreased cell survival and programmed cell death of MPM cells}

To evaluate the importance of the described DNMT1 accumulation in MPM cells, we stably silenced the expression of DNMT1 in MPM H28 cells by a lentiviral-based RNA interference (RNAi) strategy. pLL3.7 lentiviral vector was used to constitutively express a DNMT1-targeted short hairpin RNA (shRNA) and almost 100\% of infection efficiency, in terms of GFP positivity, was reached.

Drastic decrease of viable cells was observable after 10 days of DNMT1 silencing and, after further 8 days no viable $\mathrm{H} 28$ cells could be monitored (Fig. 2a). 


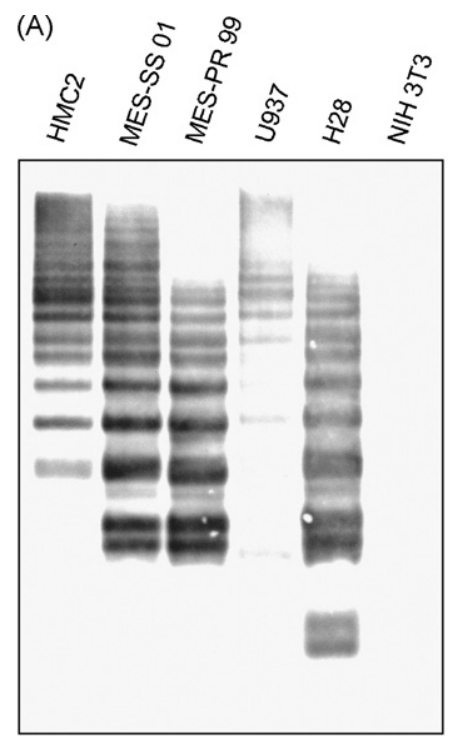

(B) 8

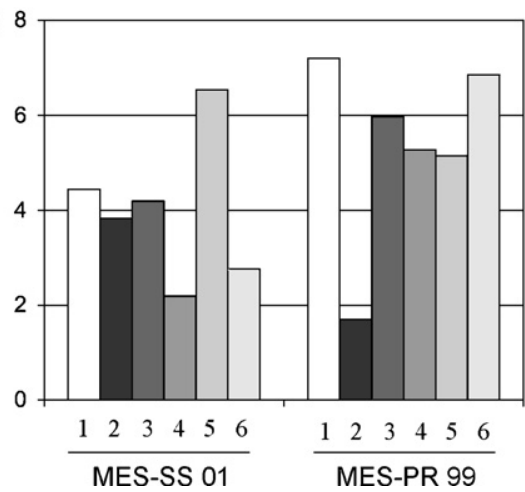

(C) 1,2

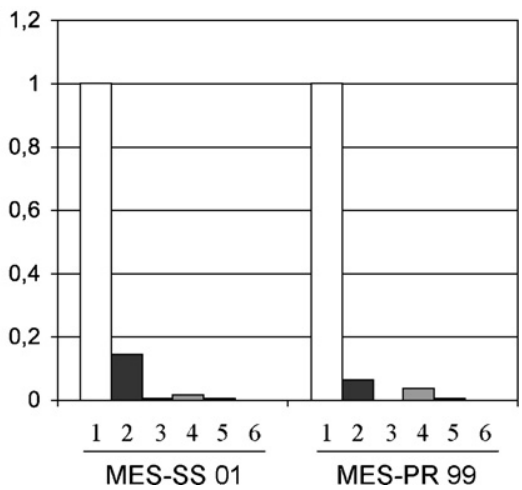

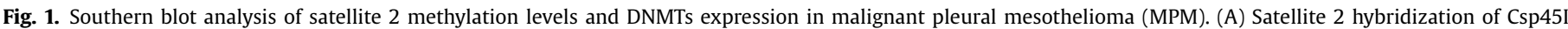

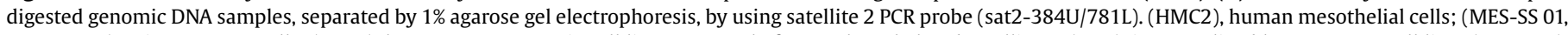

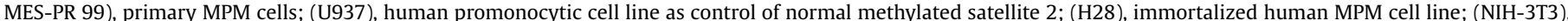

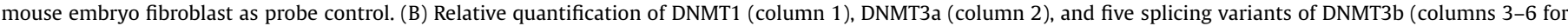

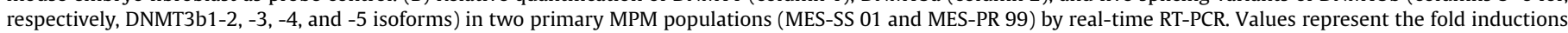

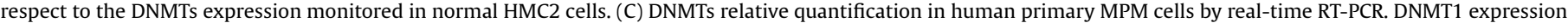
levels were considered as reference values.

DNMT1 silencing was confirmed by western blot analysis of $\mathrm{H} 28$ pLL3.7-MTsh1 infected cell lysate and, interestingly, no changes in p53 and p21 proteins expression were monitored (Fig. 2b) although the p21 transcripts were modestly increased $(1.7 \pm 0.19$ folds respect to pLL3.7 infected $\mathrm{H} 28$ cells).

To better define the biological response of $\mathrm{H} 28$ cells, the cell cycle profile of DNMT1-depleted cells was monitored and compared with not infected and empty vector infected cells, observing a conspicuous amount of hypodiploid cells (49\%) after 16 days of DNMT1 silencing, concomitantly with a genomic DNA fragmentation typical of programmed cell death (Fig. 2c and d). However, cell cycle analysis revealed only a slight increase of cells in $\mathrm{S}$ phase, an expected phenomenon since DNMT1 function is enzymatically exerted during DNA replication (Fig. 2b).

\subsection{Decitabine induces decreased cell survival, cell cycle perturbation, cell death and modulation of p21 expression in MPM cells}

In order to characterize the biological response of MPM cells to Decitabine treatment, we conducted a series of experiments by which cell survival, cell cycle alterations and apoptotic response of $\mathrm{H} 28$ cells were analyzed in both dose-response and time-course approaches. As reported in Fig. 3a, Decitabine effect on cell viability was detectable after 2 days of treatment starting at the concentration of $1 \mu \mathrm{M}$. Moreover, after 6 days, at Decitabine concentration of 1,5 , and $10 \mu \mathrm{M}$, the cell viabilities were reduced to less than $50 \%$, respect to control cells.

The following studies of cell cycle profiles and apoptotic response were performed at the Decitabine concentration of $1 \mu \mathrm{M}$. Along with accumulation of variable percentage of hypodiploid cells (10-15\%) after 6 days of treatment (Fig. 3b), important alterations of the cell cycle profile were monitored with an evident decreased of G1 phase and an increased in G2 phase percentages (Fig. 4d). In addition, H28 MPM cells, treated for 6 days with $1 \mu \mathrm{M}$ of Decitabine, were not able to form colonies if replated, suggesting a not replicating capability of the residual viable cells (Fig. 3c).

In order to verify the involvement of either p53 and p21 tumorsuppressor genes in the MPM cellular response to Decitabine, western blot analysis were performed in both time-course and dose-response experiments observing an accumulation of p21, but not 553 protein, in a dose- and time-dependent fashion (Fig. 3d and e). Furtherly, a robust p21 transcripts accumulation was observed, by real-time quantitative PCR, after 6 days of $1 \mu \mathrm{M}$ Decitabine treatment ( $12.34 \pm 0.22$ folds respect to untreated $\mathrm{H} 28$ cells). Com- 
(A)

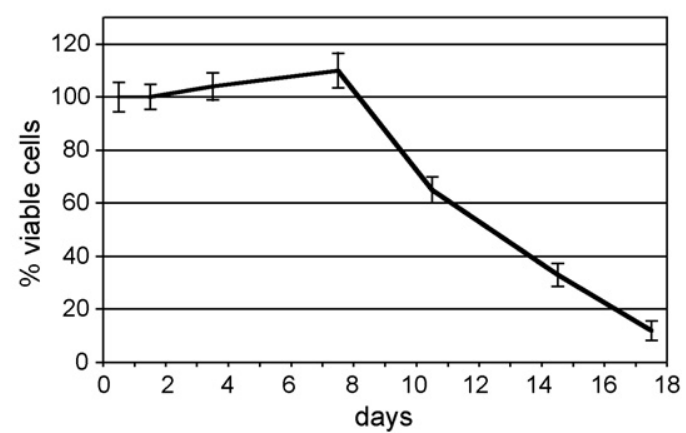

(B)

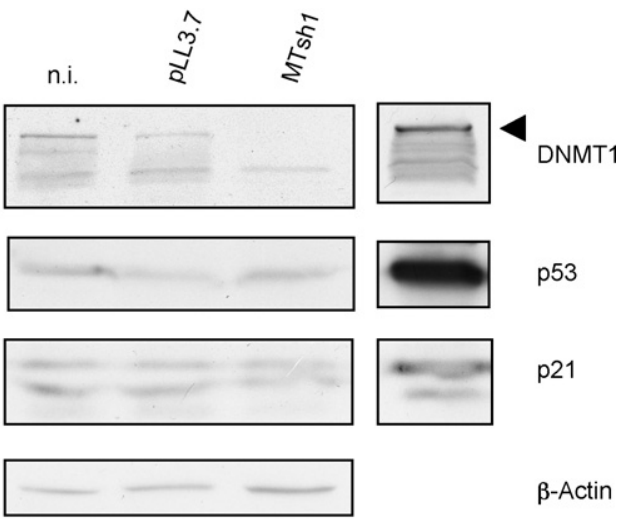

(C)
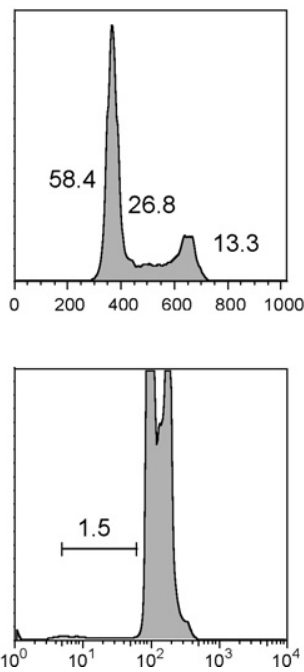
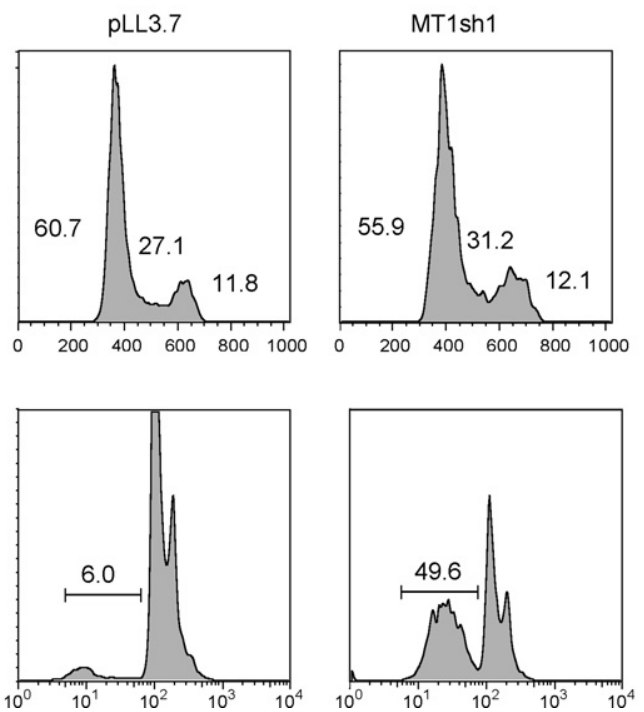

(D)

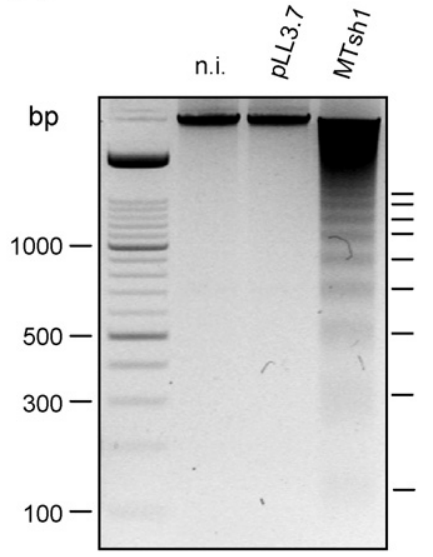

Fig. 2. DNMT1 silencing in H28 mesothelioma cell line. (A) Cell viability of stable DNMT1-silenced H28 cells, reported as percentage respect to control untreated cells. (B) Western blot analysis of $\mathrm{H} 28$ cellular populations: (n.i.), not infected cells; (pLL3.7), empty lentiviral pLL3.7 infected cells; (MTsh1), pLL3.7-MTsh1 infected cells. 293T transient transfected cell lysates for DNMT1, p53, and p21 expression were reported as positive control (right panels). Black arrow indicates the DNMT1 full-length protein. (C) Cell cycle analysis by propidium iodide staining of samples already described. The percentages of cells are reported for each phase of the cell cycle (upper panels) and for hypodiploid cells (lower panels). (D) DNA laddering assay. $5 \mu \mathrm{g}$ of genomic DNA was extracted from each sample and separated by $1 \%$ agarose gel electrophoresis.

parable results were obtained in both MES-SS 01 and MES-PR 99 primary MPM cellular populations (data not shown).

\subsection{Role of p21 upregulation in the biological response of MPM cells to Decitabine treatment}

The role of p21 upregulation in the response of MPM cells to Decitabine was investigated in a lentiviral-based silencing approach. Through the same RNAi strategy used to silence DNMT1 expression, p21 protein synthesis was stably downregulated in $\mathrm{H} 28$ MPM cells that, later on, were treated with $1 \mu \mathrm{M}$ of Decitabine for 6 days. Biochemical analysis confirmed the loss of p21 expression in pLL3.7-p21sh1 infected H28 total cell lysates (Fig. 4a). Interestingly, monitoring the cell viability in a series of time-course experiments, we first observed an evident reduction in the number of viable cells (about 50\% respect to the control after 6 days) in p21-silenced $\mathrm{H} 28$ cells (Fig. 4b). Secondly, we found that the effect of Decitabine, in terms of decreased cell survival respect to control untreated cells, was partially reduced in p21-silenced $\mathrm{H} 28$ cellular population (Fig. 4c), suggesting an involvement of p21 in the mechanisms through which Decitabine exerts its antineoplastic activity. The role of p21 in the cellular response to Decitabine was also investigated pointing the attention on the perturbation of the cell cycle profile. Intriguingly, we found that the silencing of p21 was not able to inhibit the Decitabine-dependent G2/M arrest but, on the contrary, determined per se an increase of the cells accumulated in G2/M phase of the cell cycle (Fig. 4d).

\section{Discussion}

It is overall accepted that a normal cell must acquire multiple genetic abnormalities to definitely transform in a cancer cell. The variable period of time needed for cellular transformation seems to be shorter than expected because high genomic instability, determined by mechanisms that are still not completely understood, is thought to facilitate the accumulation of these genetic aberrations. However, the discovery of structurally altered heterochromatin loci in solid tumors, characterized by loss of DNA methylation, could explain, at least in part, this phenomenon.

Interestingly, the DNA methylation status of MPM has been investigated by other authors that analyzed 28 genomic loci and found the presence of highly methylated genes [11]. To better link possible alterations of the DNA methylation levels with the already reported high genomic instability in mesothelioma cells, we focused our attention first on the methylation status of MPM cells verifying a robust decrease of DNA methylation involving megabases sized clusters of pericentromeric sequences (satellite 2). Thus, DNMTs expression was monitored trying to find a mechanism 

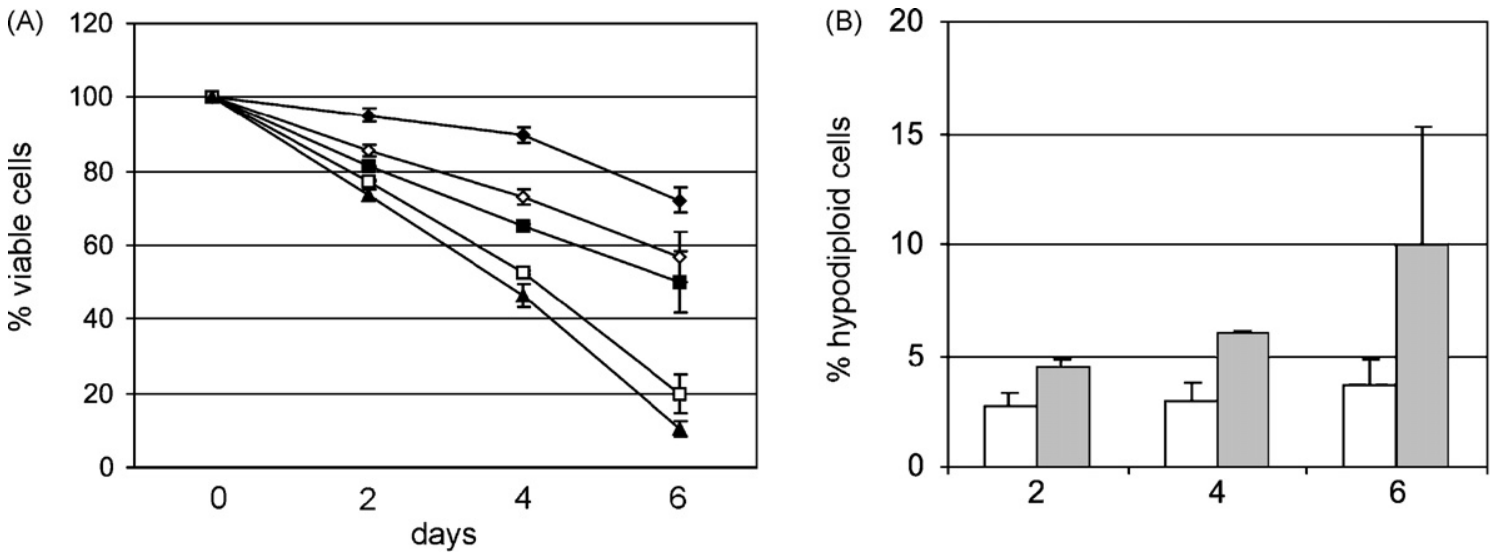

(D)

(C)

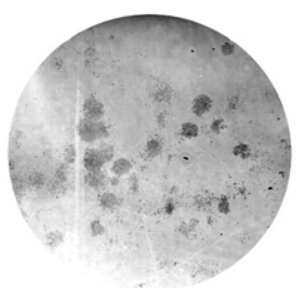

nt

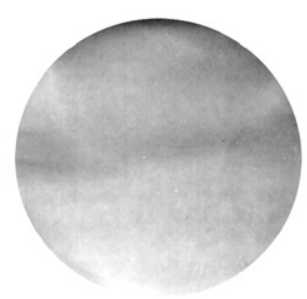

DAC
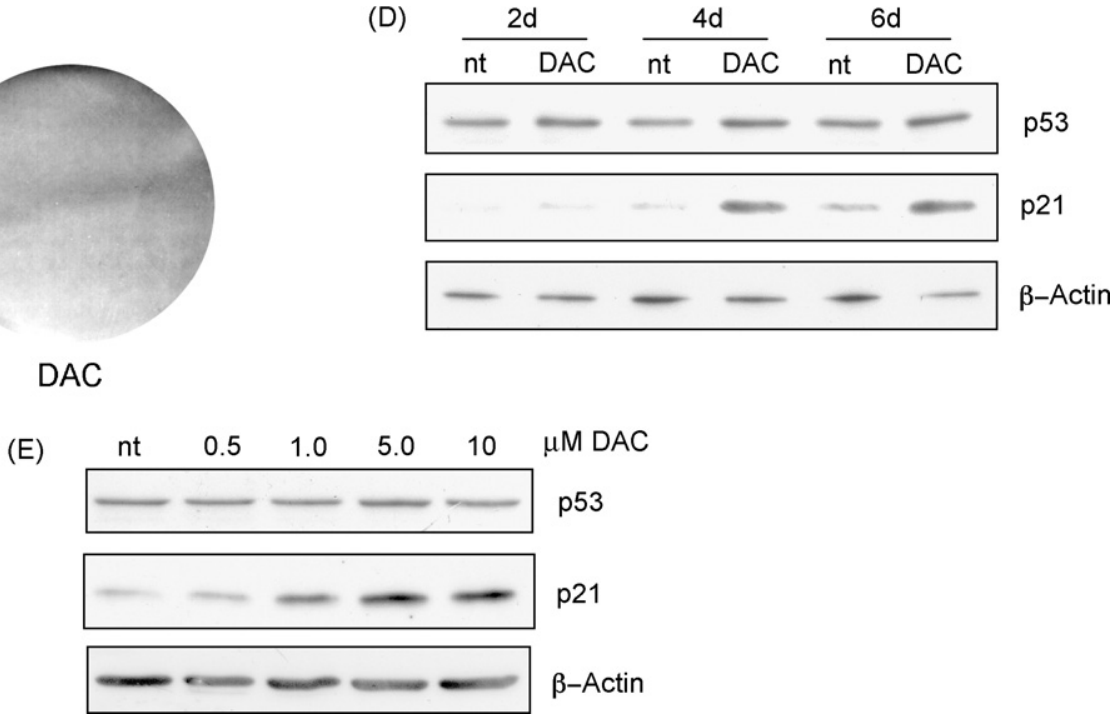

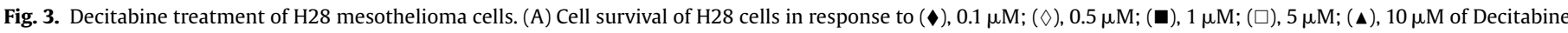

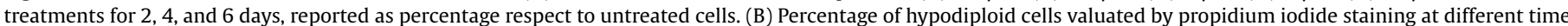

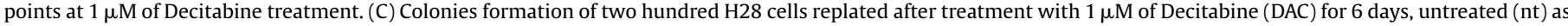

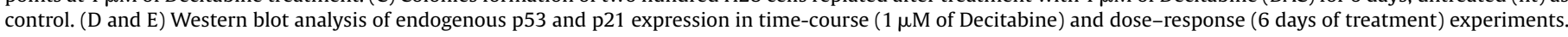
(nt) untreated, and (DAC) Decitabine-treated H28 total cell lysates.

that could explain the reported loss of global DNA methylation. Paradoxically, in MPM cells all DNMTs (DNMT1, DNMT3a, and all isoforms of DNMT3b) appear more expressed, if compared with normal mesothelial cells, and probably involved in the local hypermethylation associated with decreased expression of tumor-suppressor genes. Moreover, as often happen in tumors, DNMT1 resulted the most abundant source of DNA methyltransferase activity in malignant mesothelioma cells. In the light of these observations, we compared the stable DNMT1 silencing and the treatment with demethylating agent (Decitabine), two strategies theoretically similar in the ability to reduce the DNA methylation and considered good candidates for future therapeutic strategies, in the same biological system ( $\mathrm{H} 28$ cells). The biological response to DNMT1 silencing was monitored in H28 MPM cellular population founding a clear induction of programmed cell death, not associated with either relevant perturbation of the cell cycle or accumulation of p53 and p21 tumor-suppressor proteins, even if a slight accumulation of p21 transcripts was observed. These observations are in agreement with previous studies [25] that monitored decreased cell survival and apoptotic response of NSCLC, esophageal adenocarcinoma, and MPM cells, associated with modest upregulation of p21 transcripts, in response to DNMTs silencing.

Decitabine effects were investigated in the same cellular model performing several time-course and dose-response experiments that showed a decrease of cell survival and induction of a less dramatic apoptotic response. Similar biological alterations were monitored also in primary MPM cells (data not shown), confirming the antiproliferative activity of the demethylating drug tested. Interestingly, even after 6 days of Decitabine exposure, the cells were not able to proliferate as proved by the colony assay approach (Fig. 3c). This is an important point to discuss since Decitabine can be administered to patients only for short period of time, in consequence of the already monitored side effects and, fortunately, it seems to be anyhow sufficient to induce an irreversible biological effect, at least in vitro. This feature is even more important if considered in a contest of a possible co-treatment with other anticancer drug with which Decitabine has been demonstrated to synergise [32-34].

Differently from DNMT1 silencing, Decitabine is also able to arrest cells in G2/M phase of the cell cycle and to significantly increase the accumulation of p21 at both transcript and protein levels. The hypothetical role of p21 upregulation in Decitabine response has been investigated by silencing p21 expression in $\mathrm{H} 28$ MPM cells. The stable p21 downregulation, interestingly, induces a cellular arrest in G2/M phase and a reduced cellular proliferation of MPM cells. These phenomena could be explained with the apparent double activity of $\mathrm{p} 21$ protein that, if in one hand is able to exert the most known tumor-suppressor activity as CDK-inhibitor, in the 
(A)

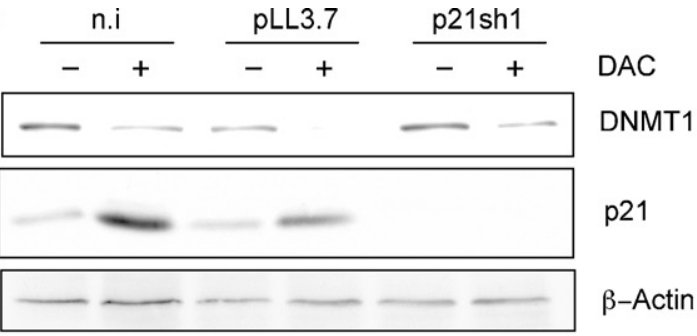

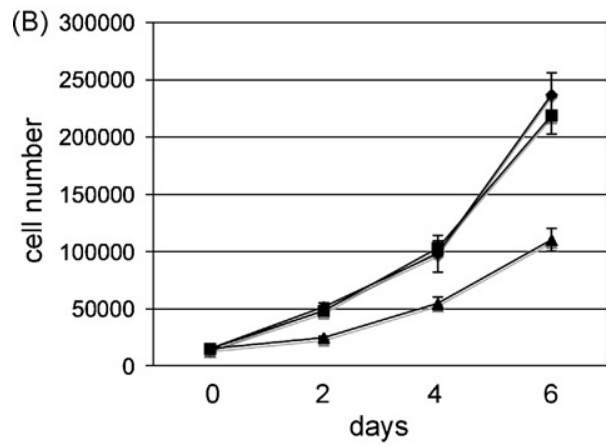

(D)
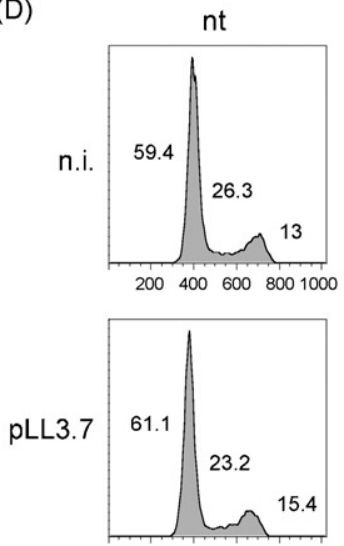

$100-400-600-8001000$

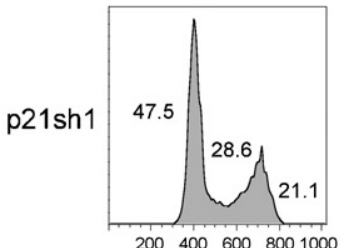

$200 \quad 400 \quad 600 \quad 8001000$

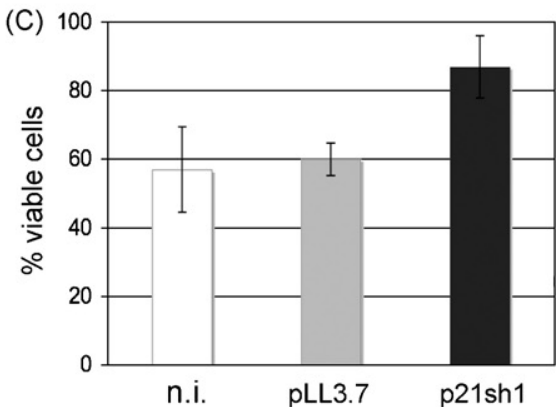

DAC
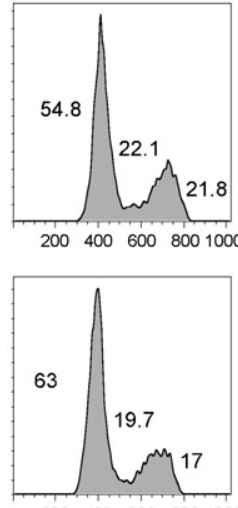

$000-4006008001000$

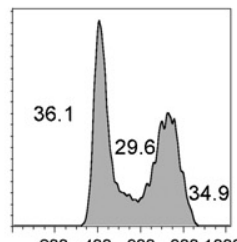

$200 \quad 400 \quad 600 \quad 8001000$

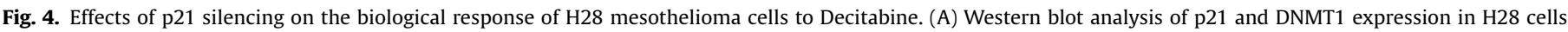

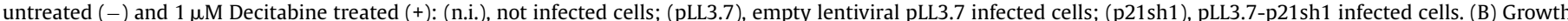

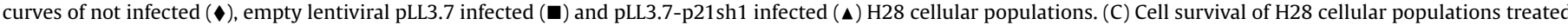

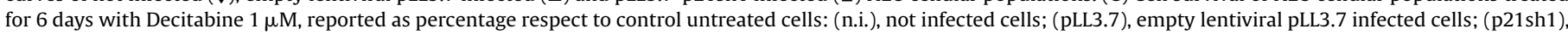

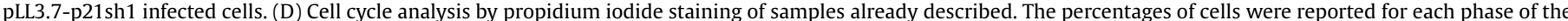
cell cycle: (nt), untreated; (DAC), $1 \mu \mathrm{M}$ Decitabine-treated cells.

other hand seems to promote cyclin B-Cdc2 kinase activity in G2/M phase, acting as a proto-oncogene [35].

Interestingly, $\mathrm{p} 21$-silenced $\mathrm{H} 28$ cells showed a consistent reduction, but not a complete abrogation, of the response to Decitabine, in terms of cell survival, respect to control cellular populations. It is also necessary to consider that the lower replication rate of p21silenced cells could decrease the incorporation of Decitabine into the genomic DNA inducing the refractariety to Decitabine treatment. However, the more efficient response to Decitabine of pLL3.7 infected cells (after 4 days of treatment, Fig. 3a), respect to p21-1cells (after 6 days of treatment, Fig. 4c) in a contest of comparable population doubling (Fig. 4b), indicates that a decreased Decitabine incorporation is not sufficient to explain the partial resistance observed in p21-silenced cells, suggesting an involvement of p21 protein in Decitabine activity. The partial protective activity of the p21 silencing suggests the possible involvement of other molecular mechanisms driving the Decitabine cellular response in addition to p21 upregulation. Moreover, it is not possible to completely dissect the role of p21 in the Decitabine response, by stable silencing strategies, because its expression is important to positive regulate the cell cycle progression. The effects of p21 silencing on the Decitabineinduced modifications of the cell cycle were also investigated, founding that the Decitabine-dependent arrest in G2/M phase is still monitorable and even more pronounced in p21-silenced cells. 
This result strongly suggests that p21 upregulation is not involved in the G2/M block induced by Decitabine.

Curiously, although Decitabine treatments determine a strong reduction of the DNMT1 protein levels (Fig. 4a), the biological response of MPM cells to this drug appears quite different respect that observed in the DNMT1 silencing experiments. These results suggest that the conspicuous decreased DNMT1 enzymatic activity in Decitabine-treated cells could be considered a secondary aspect of the biological response to the demethylating agent.

However, DNMT1 silencing remains a good therapeutic target in mesothelioma, and also in other kinds of tumor, for two reasons: first of all, solid tumors are characterized by DNMT1 protein upregulation, probably necessary to sustain both faster cellular proliferation and local DNA hypermethylation. Secondly, since DNMT1 silencing exerts its antiproliferative activity through a different mechanism respect to Decitabine, it can be considered an effective alternative (or also additional) approach for cancer treatment, especially for cases in which demethylating agents cannot be used.

\section{Conflict of interest statement}

There is no conflict of interest.

\section{Acknowledgements}

Paola and Rodica, the inspiration of our present and future effort against cancer.

We thank Dr. Sara Orecchia for providing histological samples and Prof. Mauro Magnani for its crucial support.

\section{Appendix A. Supplementary data}

Supplementary data associated with this article can be found, in the online version, at doi:10.1016/j.lungcan.2009.01.015.

\section{References}

[1] Lee WC, Testa JR. Somatic genetic alterations in human malignant mesothelioma. Int J Oncol 1999;14:181-8.

[2] Murthy SS, Testa JR. Asbestos, chromosomal deletions, and tumor suppressor gene alterations in human malignant mesothelioma. J Cell Physiol 1999;180:150-7.

[3] Ehrlich M. DNA methylation in cancer: too much, but also too little. Oncogene 2002;21:5400-13.

[4] Fanelli M, Caprodossi S, Ricci-Vitiani L, Porcellini A, Tomassoni-Ardori F, Amatori $\mathrm{S}$, et al. Loss of pericentromeric DNA methylation pattern in human glioblastoma is associated with altered DNA methyltransferases expression and involves the stem cell compartment. Oncogene 2008;27:358-65.

[5] Tsuda H, Takarabe T, Kanai Y, Fukutomi T, Hirohashi S. Correlation of DNA hypomethylation at pericentromeric heterochromatin regions of chromosomes 16 and 1 with histological features and chromosomal abnormalities of human breast carcinoma. Am J Pathol 2002;161:859-66.

[6] Vilain A, Vogt N, Dutrillaux B, Malfoy B. DNA methylation and chromosome instability in breast cancer cell lines. FEBS Lett 1999;460:231-4.

[7] Destro A, Ceresoli GL, Baryshnikova E, Garassino I, Zucali PA, De Vincenzo F, et al. Gene methylation in pleural mesothelioma: correlations with clinico-pathological features and patient's follow-up. Lung Cancer 2008;59: 369-76

[8] Shivapurkar N, Toyooka S, Toyooka KO, Reddy J, Miyajima K, Suzuki M, et al. Aberrant methylation of trail decoy receptor genes is frequent in multiple tumor types. Int J Cancer 2004;109:786-92.

[9] Taguchi T, Jhanwar SC, Siegfried JM, Keller SM, Testa JR. Recurrent deletions of specific chromosomal sites in 1p, 3p, 6q, and 9p in human malignant mesothelioma. Cancer Res 1993;53:4349-55.

[10] Toyooka S, Carbone M, Toyooka KO, Bocchetta M, Shivapurkar N, Minna JD, et al. Progressive aberrant methylation of the RASSF1A gene in simian virus 40 infected human mesothelial cells. Oncogene 2002;21:4340-4.
[11] Tsou JA, Galler JS, Wali A, Ye W, Siegmund KD, Groshen S, et al. DNA methylation profile of 28 potential marker loci in malignant mesothelioma. Lung Cancer 2007;58:220-30.

[12] Wong L, Zhou J, Anderson D, Kratzke RA. Inactivation of p16INK4a expression in malignant mesothelioma by methylation. Lung Cancer 2002;38:131-6.

[13] Hansen RS, Wijmenga C, Luo P, Stanek AM, Canfield TK, Weemaes CMR, et al. The DNMT3B DNA methyltransferase gene is mutated in the ICF immunodeficiency syndrome. Proc Natl Acad Sci USA 1999;96:14412-7.

[14] Okano M, Bell DW, Haber DA, Li E. DNA methyltransferases Dnmt3a and Dnmt3b are essential for de novo methylation and mammalian development. Cell 1999;99:247-57.

[15] Xu GL, Bestor TH, Bourc'his D, Hsieh CL, Tommerup N, Bugge M, et al. Chromosome instability and immunodeficiency syndrome caused by mutations in a DNA methyltransferase gene. Nature 1999;402:187-91.

[16] Saito Y, Kanai Y, Sakamoto M, Saito H, Ishii H, Hirohashi S. Overexpression of a splice variant of the DNA methyltransferase 3b, DNMT3b4, associated with DNA hypomethylation on pericentromeric satellite regions during human hepatocarcinogenesis. Proc Natl Acad Sci USA 2002;99:10060-5.

[17] Issa JPJ, Garcia-Manero G, Giles FJ, Mannari R, Thomas D, Faderl S, et al. Phase I study of low-dose prolonged exposure schedules of the hypomethylating agent 5-aza-2'deoxycytidine (decitabine) in hematopoietic malignancies. Blood 2004; 103:1635-40.

[18] Mund C, Brueckner B, Lyko F. Reactivation of epigenetically silenced genes by DNA methyltransferase inhibitors: basic concepts and clinical applications. Epigenetics 2006;1:7-13.

[19] Saba HI, Wijermans PW. Decitabine in myelodysplastic syndromes. Semin Hematol 2005;42:S23-31.

[20] Jiemjit A, Fandy TE, Carraway H, Bailey KA, Baylin S, Herman JG, Gore SD. p21WAF1/CIP1 induction by 5-azacytosine nucleosides requires DNA damage. Oncogene 2008, doi:10.1038/sj.onc.1211018.

[21] Aparicio A, Eads CA, Leong LA, Laird PW, Newman EM, Synold TW, et al. Phase I trial of continuous infusion 5-aza-2'-deoxycytidine. Cancer Chemother Pharmacol 2003;51:231-9.

[22] Schrump DS, Fischette MR, Nguyen DM, Zhao M, Li X, Kunst TF, et al. Phase I study of Decitabine-mediated gene expression in patients with cancers involving the lungs, esophagus, or pleura. Clin Cancer Res 2006;12:5777-85.

[23] Saikawa Y, Kubota T, Maeda S, Otani Y, Kumai K, Kitajima M. Inhibition of DNA methyltransferase by antisense oligodeoxynucleotide modifies cell characteristics in gastric cancer cell lines. Oncol Rep 2004;12:527-31.

[24] Suzuki M, Sunaga N, Shames DS, Toyooka S, Gazdar AF, Minna JD. RNA interference-mediated knockdown of DNA methyltransferase 1 leads to promoter demethylation and gene re-expression in human lung and breast cancer cells. Cancer Res 2004;64:3137-43.

[25] Kassis ES, Zhao M, Hong JA, Chen GA, Nguyen DM, Schrump DS. Depletion of DNA methyltransferase 1 and/or DNA methyltransferase 3b mediates growth arrest and apoptosis in lung and esophageal cancer and malignant pleural mesothelioma cells. J Thorac Cardiovasc Surg 2006;131:298-306.

[26] Orecchia S, Schillaci F, Salvio M, Libener R, Betta PG. Aberrant E-cadherin and $\gamma$ catenin expression in malignant mesothelioma and its diagnostic and biological relevance. Lung Cancer 2004;45:S37-43.

[27] Caprodossi S, Pedinotti M, Amantini C, Santoni G, Minucci S, Pelicci PG, et al. Differentiation response of acute promyelocytic leukemia cells and PML/RAR $\alpha$ leukemogenic activity studies by real-time RT-PCR. Mol Biotechnol 2005;30:231-8.

[28] Rubinson DA, Dillon CP, Kwiatkowski AV, Sievers C, Yang L, Kopinja J, et al. A lentivirus-based system to functionally silence genes in primary mammalian cells, stem cells and transgenic mice by RNA interference. Nat Genet 2003;33:401-6.

[29] Fanelli M, Fantozzi A, De Luca P, Caprodossi S, Matsuzawa S, Lazar MA, et al. The coiled-coil domain is the structural determinant for mammalian homologues of Drosophila Sina-mediated degradation of promyelocytic leukemia protein and other tripartite motif proteins by the proteasome. J Biol Chem 2004;279:5374-9.

[30] Lee C, Wevrick R, Fischer RB, Ferguson-Smith MA, Lin CC. Human centromeric DNAs. Hum Genet 1997; 100:291-304.

[31] Prosser J, Frommer M, Paul C, Vincent PC. Sequence relationships of three human satellite DNAs. J Mol Biol 1986;187:145-55.

[32] Morita S, Iida S, Kato K, Takagi Y, Uetake H, Sugihara K. The synergistic effect of 5-aza-2'-deoxycytidine and 5-fluorouracil on drug-resistant tumors. Oncology 2006;71:437-44.

[33] Xu J, Zhou JY, Tainsky MA, Wu GS. Evidence that tumor necrosis factor-related apoptosis-inducing ligand induction by 5 -Aza-2'-deoxycytidine sensitizes human breast cancer cells to adriamycin. Cancer Res 2007;67:1203-11.

[34] Yang X, Phillips DL, Ferguson AT, Nelson WG, Herman JG, Davidson NE. Synergistic activation of functional estrogen receptor (ER)-alpha by DNA methyltransferase and histone deacetylase inhibition in human ER-alphanegative breast cancer cells. Cancer Res 2001;61:7025-9.

[35] Dash BC, El-Deiry WS. Phosphorylation of p21 in G2/M promotes cyclin B-Cdc2 kinase activity. Mol Cell Biol 2005;25:3364-87. 